\title{
Eleição de Diretores de Escolas Públicas: Avanços e Limites da Prática*
}

\author{
Vitor Henrique Paro \\ Universidade de São Paulo (Usp)
}

Com base em pesquisa de campo que estudou a introdução do sistema de eleição de diretores de escolas públicas básicas, em vários sistemas de ensino no Brasil, o artigo examina alguns limites da experiência eletiva nas escolas e discute aspectos relacionados ao impacto das eleições sobre o papel do diretor e sobre a prática democrática na gestão da escola pública.

Em pesquisa recentemente concluída," envolvendo trabalho de campo e exame da bibliografia pertinente ao tema, analisei experiências de eleição de diretores de escolas de $1^{\circ}$ e $2^{\circ}$ graus em diversos Estados e municípios do Brasil, com o fim de estudar suas características e os problemas de sua institucionalização e implementação, bem como captar seus efeitos sobre a democratização da gestão escolar e sobre a qualidade e quantidade na oferta de ensino. No Relatório Final da pesquisa (Paro, 1996) encontram-se a metodologia utilizada e a discussão dos resultados alcançados. Com base nessa investigação, o presente artigo tem o

\footnotetext{
* Trabalho apresentado na 19" Reunião Anual da Associação Nacional de Pós-Graduação e Pesquisa em Educação (Anped), realizada em Caxambu-MO, de 22 a 26 de setembro de 1996. Publicado originalmente na Revista Portuguesa de Educação, Universidade do Minho, Braga, Portugal, v.10, n.2, 1997. Agradecemos à citada revista a autorização para sua republicação na $R B E P$.

** A pesquisa desenvolveu-se no Departamento de Administração Escolar e Economia da Educação da Faculdade de Educação da Universidade de São Paulo (Usp) e contou com o apoio financeiro do CNPq.
} 
propòsito de examinar alguns limites da experiência eletiva nas escolas, bem como discutir aspectos relacionados ao impacto das eleições sobre o papel desempenhado pelo diretor e sobre a prática democrática na gestão da escola pública.

\section{Os limites do sistema eletivo}

Embora algumas experiências localizadas remontem à década de 60, a reivindicação da escolha de diretores escolares por meio de processo eletivo, em âmbito nacional, é fenômeno que se inicia nos começos da década de 80 , no contexto da redemocratização política do país. Em vários Estados, iniciam-se processos de eleição de diretores escolares na primeira metade dessa década, com a ascensão dos primeiros governadores estaduais eleitos, após a ditadura iniciada em 1964. Em 1989, vários Estados inscrevem em suas constituições a obrigatoriedade da eleição como critério de escolha dos diretores nas escolas públicas. Entretanto, já ao final da década de 80 e início da de 90 , verifica-se certo refluxo das eleições em alguns Estados, produto da ação de governos pouco comprometidos com a democracia, que entram com Ações Diretas de lnconstilucionalidade contra as eleições, com a clara intenção de proteger seus interesses político-partidários identificados com práticas clientelistas.

Apesar disso, porém, a adoção de processo eletivo como critério para escolha de diretores expande-se em todo o país, fazendo-se realidade em grande número de municípios e em Estados onde antes vigorava a nomeação política. Em alguns sistemas que já haviam experimentado a escolha democrática dos diretores, como o Estado do Paraná e o Distrito Federal, os governadores eleitos em 1994 voltam a introduzir a eleição direta, em cumprimento a suas plataformas de governos ou a promessas feitas em suas campanhas eleitorais. O fato, aliás, de os políticos passarem a inscrever em suas plataformas eleitorais o compromisso com a eleição de diretores indica sua sensibilidade para algo que passou a fazer parte 
dos desejos de parcelas da população envolvidas com a gestão da escola pública. Este parece ser mais um resultado positivo do movimento em torno da eleição de diretores que se verificou a partir de inícios da década de 80: o de inscrever-se no imaginário dessas parcelas da população a escolha democrática de diretores escolares como um valor positivo e como um direito a ser reivindicado.

Mas, como toda inovação, a perspectiva de introdução da via eletiva para escolha de diretores escolares provoca grande número de expectativas nos sujeitos envolvidos, muitas delas impossíveis de serem realizadas. Por isso, é importante ter presente algumas limitações apontadas pela prática. A seguir comentarei como se manifestaram, nas experiências examinadas, os limites das eleições de diretores, com respeito a algumas expectativas que se tinha a seu respeito.

Um dos principais argumentos para a implantação das eleições de diretores fundamenta-se na crença na capacidade do sistema eletivo de neutralizar as práticas tradicionalistas calcadas no clientelismo e no favorecimento pessoal, que inibem as posturas universalistas, reforçadoras da cidadania. A esse respeito, parece que as eleições tiveram um importante papel na diminuição ou eliminação, nos sistemas em que foram adotadas, da sistemática influência dos agentes políticos (vereadores, deputados, prefeitos, cabos eleitorais), etc. na nomeação do diretor. Mas, isso não significa que o clientelismo tenha deixado de exercer suas influências na escola. Por um lado, em alguns sistemas, continuaram a existir brechas para a penetração da influência do agente político na nomeação do diretor; por outro, as práticas clientelistas passaram a fazer parte também do interior da própria escola, quer no processo de eleição do diretor, quer durante o exercício de seu mandato.

Verificou-se certa permanência da influência político-partidária, especialmente nos sistemas em que a eleição se deu por lista tríplice, com a escolha definitiva de um dos três nomes, por conta do poder executivo. No Estado do Paraná, nas eleições de 1983, Zabot (1984, 
p.89) refere-se às "inúmeras iniciativas dos grupos de pressão interessados na nomeação de determinados candidatos". Também no Município de Goiânia, Canesin (1993, p. 127-128) reporta as "marcas profundas do clientelismo" presente nas primeiras eleições, práticas também referidas em Dourado (1990, p. 123).

Mas, não só nos locais em que havia a escolha por lista tríplice esteve presente a pressão clientelista. Especialmente nas primeiras eleições, os agentes políticos não desistem de tentar fazer valerem seus interesses clientelistas. É o caso, por exemplo, do Estado de Minas Gerais onde, apesar da existência de regras bem definidas e divulgadas, ainda houve assédio de políticos para burlá-las. (Mello, Silva, 1994, p.32).

Uma peculiar forma de intervir movida por interesses clientelistas é a praticada por certos agentes políticos que, alijados, pelo sistema eletivo, de sua anterior oportunidade de influir diretamente na nomeação dos dirigentes escolares, prevalecem-se de sua experiência política para influenciar no próprio processo de eleição que se dá na unidade escolar. Calaça, em estudo realizado na rede municipal de ensino de Goiânia, dá conta de práticas desse tipo na eleição de 1984, nesse município, ao informar que "alguns candidatos patrocinados por vereadores distribuíram santinhos, calendários e camisetas e prometeram favores em troca de votos" (Calaça, 1993, p.88).

Também no interior da própria unidade escolar, segundo reclamações do pessoal que aí trabalha, podem ser identificadas ocorrências de práticas mais tradicionalistas que se supunham superadas com a eleição. Um dos professores entrevistados por Castro et al., no Estado do Rio Grande do Sul, declara que continua a haver as "panelinhas" existentes antes das eleições (Castro et al., 1991, p.98). Por seu turno, Holmesland et al. (1989, p.128) também apresentam depoimentos de diretores que evidenciam uma concepção clientelista do pessoal escolar, que exige uma contrapartida pessoal ao apoio dado na eleição. 
O fato, entretanto, de a incipiente prática política introduzida pelas eleições de diretores não ter sido capaz de eliminar por completo essas expectativas e comportamentos clientelistas não pode levar a que se impute às eleições as causas desses males que nada mais são, na verdade, do que remanescentes de uma cultura tradicionalista que só a prática da democracia e o exercício autônomo da cidadania poderão superar.

Outra expectativa que muitas pessoas tinham com relação à eleição era a de que esta conseguiria eliminar o autoritarismo existente na escola e a falta de participação de professores, alunos, funcionários e pais nas decisões. A suposição por trás dessa expectativa era a de que a falta de participação e o autoritarismo existentes na escola se deviam, em grande parte ou exclusivamente, ao fato de o diretor, não tendo compromissos com o pessoal escolar ou com os usuários da escola, por não ter sido escolhido por estes, tendia a articular-se apenas com os interesses do Estado, voltando as costas para a unidade escolar e sua comunidade. Com a eleição, esperavam que a escola se encaminhasse rapidamente para uma convivência democrática e para a maior participação de todos em sua gestão. Todavia, as experiências mostraram que havia mais otimismo do que realismo nessas previsões. Numa apreciação dessa questão no Distrito Federal, após as eleições, no período de 1985 a 1988, Couto (1988, p.145) constata a falta de avanços na participação dos vários segmentos escolares na escola de modo a implicar a distribuição do poder. Em Vitória, segundo técnicas da Secretaria de Educação, apesar dos avanços, ainda há muita reclamação a respeito do diretivismo e do autoritarismo do diretor. Em Goiânia, Dourado (1990, p. 136) também constata a resistência de professores e diretores em aceitar as tentativas de se instalarem Grêmios Estudantis e "outros canais de participação na escola".

Obviamente, as pessoas que pensavam que, com as eleições, o diretor mudaria seu comportamento, de forma radical e imediata, 
frustraram-se ao perceber que muito das características do chefe monocrático, que detém a autoridade máxima na escola, persistiu mesmo com a eleição. Mas, o que isso reafirma é que as causas do autoritarismo existente nas unidades escolares não advém exclusivamente do provimento do diretor pela via da nomeação política. Antes, é preciso considerar que tal autoritarismo é resultado da conjunção de uma série de determinantes internos e externos à unidade escolar que se sintetizam na forma como se estrutura a própria escola e no tipo de relações que aí têm lugar. Por isso, mais uma vez é preciso ter presente que, também neste caso, não se trata em absoluto de culpar a eleição, mas de reconhecer que ela tem limites que só podem ser superados, quando se conjuguem ao processo eletivo outras medidas que atinjam a própria organização do trabalho e a distribuição da autoridade e do poder na escola.

Outra circunstância que evidencia os limites da eleição de diretores é que ela não está imune ao corporativismo, por parte dos grupos que interagem na escola. A esse respeito, o maior número de reclamações contidas em relatos de autoridades das secretarias de educação e de pessoas envolvidas nas mudanças refere-se à atitude de professores que, pouco afeitos às regras da democracia que supõem que o eleito, embora escolhido pela maioria, deve governar visando ao bem de todos, procuram tirar proveito da situação, buscando favorecimento ao grupo dos docentes, em troca de seu apoio a determinado candidato.

Finalmente, uma importante característica das eleições é que, como todo processo de democracia, a participação e o envolvimento das pessoas, enquanto sujeitos na condução das ações, é apenas uma possibilidade, não uma garantia. Especialmente em sociedades com fortes marcas tradicionalistas, sem uma cultura desenvolvida de participação social, é muito difícil conseguir-se que os indivíduos não deleguem a outros aquilo que faz parte de sua obrigação, enquanto sujeito partícipe da ação coletiva. No caso da escola pública, as reclamações, especialmente de diretores, dão conta de que a eleição do dirigente acaba, em grande medida, significando não a escolha de um líder para a coordenação do esforço humano coletivo na escola, mas muito mais como 
uma oportunidade de jogar sobre os ombros do diretor toda a responsabilidade que envolve a prática escolar. Dourado (1990, p.139) refere-se a esse tipo de situação como a uma redução do processo democrático a "mera delegação de poderes" e Holmesland et al. (1989, p. 138) consideram que "o diretor de escola pública, mesmo eleito, é um indivíduo que tende a sentir-se desacompanhado, desprotegido, solitário".

Não há dúvida de que, se o problema é a falta de tradição democrática, é com a insistência em mecanismos de participação e de exercício da democracia que se conseguirá maior envolvimento de todos em suas responsabilidades. Mas, diante da associação que muitos fazem entre o direito de votar e a omissão em co-participar das responsabilidades do eleito, nunca é demais meditar sobre as palavras de Agnès Heller sobre a questão da relação entre liberdade e dever:

Toda pessoa tem a liberdade de não reconhecer nenhum valor moral. Mas, como já disse, isso não a ajuda a ser livre. Hegel tinha razão quando distinguiu entre liberdade e arbítrio. A liberdade é sempre liberdade para algo, e não apenas liberdade de algo. Se interpretarmos a liberdade apenas como o fato de sermos livres de alguma coisa, encontramo-nos no estado de arbítrio, definimo-nos de modo negativo.

A liberdade é uma relação e, corno tal, deve ser continuamente ampliada.

O próprio conceito de liberdade contém o conceito de dever, o conceito de regra, de reconhecimento, de intervenção recíproca. Com efeito, ninguém pode ser livre se, em volta dele, há outros que não o são. (Heller, 1982, p. 155; grifos no original)

\section{A nova situação do diretor}

Passar de uma situação clientelista, onde o que vale é o critério político-partidário, para uma situação de escolha democrática, legitimado pela vontade dos sujeitos envolvidos na situação escolar, faria supor, para muitos, mudanças significativas no perfil do diretor da escola pública 
básica. Entretanto, se assim aconteceu, isto não foi percebido de modo inequívoco pelos que compartilham de alguma forma o espaço escolar. O processo de escolha é apenas um dos múltiplos determinantes a influir na maneira de gerir a escola e, em especial, no modo de agir do próprio diretor. Além disso, se, por um lado, a eleição pressupõe mudanças de condutas do diretor (movidas, especialmente, pelo compromisso que a eleição provoca com os eleitores), por outro, os inúmeros problemas da gestão escolar, que permanecem, contribuem para dificultar a percepção das mudanças ocorridas. Isto sem falar em problemas novos que surgem em substituição a antigos. Um desses novos problemas é referido por Castro et al. quando apresentam as dificuldades do novo diretor para ter acesso aos órgãos centrais do sistema escolar:

Quando o sistema era clientelistico, o diretor era escolhido com base em critérios políticos e tinha uma forma de relacionamento baseada nesta indicação política. Com a eleição de diretores, isto se modifica e o velho sistema entra em desuso, mas uma nova forma de relacionamento está em processo de formação e assim o diretor eleito tem muito menos acesso às fontes de poder - à Secretaria de Obras do Estado e aos contados políticos tradicionais. O diretor eleito enfrenta, além de todas as dificuldades inerentes à função, a de construir uma nova forma de relacionamento com os órgãos superiores num breve período de mandato (Castro et al., 1991, p. 101).

Em Holmesland et al. (1989, p.132 seq.), encontram-se evidências de que, apesar da eleição, o diretor continua numa situação de dubiedade, entre o poder do Estado e as reivindicações da escola. Sente que tem obrigação para com o Estado, mas, ao mesmo tempo, recebe pleitos de seus liderados que entram em contradição com as determinações do sistema superior de autoridade, e se vê em conflito, pois não pode deixar de ouvir aqueles que o elegeram. Sente, por isso, que era mais fácil a situação anterior em que recebia determinações superiores e as impunha aos seus comandados, sem maiores dificuldades. 
Essa situação não deixa de ser reveladora de uma contradição originária do próprio processo democrático de escolha do diretor. Mas, parece que esta é precisamente uma qualidade que se busca com a instituição da eleição: que as contradições venham à tona e, no caso do diretor, que este seja, pelo menos em parte, desarticulado do poder autoritário do Estado e se articule com os interesses da escola.

Parece que o diretor consegue perceber melhor, agora, sua situação contraditória pelo fato de ser mais cobrado pelos que o elegeram. Este é um fato novo que não pode ser menosprezado. A sua condição de responsável último pela escola e de preposto do Estado, no que tange ao cumprimento da lei e da ordem na instituição escolar, soma-se agora seu novo papel de líder da escola, legitimado democraticamente pelo voto de seus comandados, que exige dele maior apego aos interesses do pessoal escolar e dos usuários, em contraposição ao poder do Estado. Isso serviu para introduzir mudanças na conduta dos diretores eleitos, que passaram a ver com maior cuidado as solicitações de professores, funcionários, alunos e pais. Um membro da diretoria do Fórum Paranaense em Defesa da Escola Pública, Gratuita e Universal considera que, se a eleição não mudou o papel do diretor, pelo menos o afetou, servindo para quebrar "a marca autoritária presente na relação entre a direção da escola e o corpo docente, discente, etc." Considera ele que houve maior proximidade entre diretor e professores bem como com funcionários, alunos e pais e cita como exemplo a maior facilidade e possibilidade de existência dos grêmios estudantis, que eram muito dificultados anteriormente e que passaram a ser vistos com maior simpatia pela direção.

Uma evidência da maior aproximação do diretor com o corpo docente foi sua mudança de atitude, com relação aos movimentos grevistas dos professores. Holmesland et alii. assim se referem à postura dos professores no Estado do Rio Grande do Sul:

O sentimento de não cooptação por parte dos diretores parece ser bastante forte e se tornou mais evidente por ocasião das greves gerais de magistério. No Rio Grande do Sul os diretores tomaram o partido dos professores e foram juntos à praça pública. Por essas razões a hierarquia do sistema de 
ensino tenha, talvez, se sentido ameaçada, percebendo a eleição como um fator desestruturante de sua posição de poder (Holmesland et al., 1989, p.164).

Antes, era praxe o diretor nomeado encaminhar listas com os nomes dos professores em greve, sempre que solicitado pelas autoridades superiores. Com a eleição do dirigente escolar, essa prática passou a ser questionada e negada pelo diretor, que passou a reivindicar melhor tratamento dos governos aos movimentos grevistas. Um exemplo típico dessa nova postura é relatado por Calaça, referindo-se à greve no sistema municipal de ensino de Goiânia, no início do segundo semestre de 1983:

Nesse confronto aberto, o prefeito contava apenas com o apoio de um bloco pequeno de vereadores que exigia dele a demissão imediata dos grevistas. Já os 83 diretores, na condição de eleitos pela comunidade escolar posicionaram-se contra a decisão do prefeito Nion e defendiam o diálogo; alguns vereadores e a Secretária da Educação cobravam do prefeito as promessas de palanque do PMDB e o pressionavam para resolver o impasse que ele próprio criou (Calaça, 1993, p.74).

Em Santa Catarina, em 1987, conforme relatado por Leal e Silva, os diretores assumem posição semelhante, ao emitirem o chamado "Manifesto dos Diretores das Escolas Estaduais de Santa Catarina", resultante de assembléia realizada em 4 de junho, em Florianópolis:

Outro aspecto que a leitura do Manifesto e da ata da assembléia revela é a posição de mediadores que os diretores parecem assumir. Colocam-se numa clara posição de defesa dos professores e de seus direitos, na medida em que consideram suas reivindicações justas e legítimas e decidem não encaminhar, às instâncias superiores, as listas com os nomes dos professores grevistas, solicitadas pelo governo. Ao mesmo tempo, exercem pressão sobre o governo para que apresse os entendimentos com as associações, cumpra a legislação em vigor e não puna os professores em greve (Leal, Silva, 1987, p.71-72). 
Todavia, parece que a nova situação ainda não teve a qualidade de dotar o diretor e a escola de um novo poder de barganha diante do próprio Estado que, habituado a agir clientelisticamente no atendimento às unidades escolares, com a ausência do clientelismo, se acomoda, simplesmente não dando ouvidos às solicitações do diretor. De qualquer forma, o ter conseguido nova postura, pelo menos do diretor, parece ser uma conquista do processo eletivo que não se deve menosprezar. Além disso, há indícios de que os próprios diretores consideram a nova situação mais positiva para a administração da escola.

É interessante observar que a eleição de diretores não apenas traz novas determinações ao papel do diretor, mas, em muitos casos, possibilita o acesso ao cargo a um novo contingente de professores que, pelo critério da nomeação clientelista, dificilmente viriam a se tornar dirigentes escolares. Ao mesmo tempo, deve-se observar também que o antigo diretor era mais identificado com as obrigações burocráticas e não tinha um passado de escolha livre por seus comandados como estímulo para defender mecanismos democráticos como passa a ter o diretor eleito.

Finalmente, nota-se que, com a menor preocupação com as questões mais propriamente burocráticas, ganha espaço na pauta de ocupações do diretor a atenção ao pedagógico. A função de direção, anteriormente enredada em múltiplas atividades destinadas a atender às solicitações dos órgãos superiores, pouco relacionadas com as atividadesfim da escola, de repente se sente também pressionada a dedicar-se com maior cuidado ao pedagógico que, afinal de contas, foi objeto de todos os discursos nas campanhas para a eleição. $O$ processo eletivo, dessa forma, não apenas favorece o comprometimento com a razão de ser da escola, ou seja, o educativo, por parte dos candidatos, mas também propicia a colocação em evidência do pedagógico nas discussões que se fazem, por parte de todos, em torno da questão diretiva. Como conseqüência, parece estar ganhando maior relevo, tanto nas 
preocupações dos diretores eleitos quanto nas exigências de seus liderados, a atenção com as atividades pedagógicas da escola. Na pesquisa de campo, isso transpareceu no depoimento do pessoal escolar bem como de outras pessoas envolvidas nas experiências.

Essa constatação é muito importante porque acena para uma nova orientação na prática diretiva escolar, que deixa de identificar-se com uma praxis "burocratizada" no sentido que lhe dá Sánchez Vázquez (1977, p.260 seq.), de prática reiterativa, como um fim em si mesma, passando a constituir-se prática mediadora que, em seu caráter administrativo de "utilização racional de recursos para a realização de fins determinados" (Paro, 1986, p. 18), instrumentaliza a consecução dos objetivos educativos da instituição escolar.

\section{Democracia na escola}

Um ponto positivo a creditar à introdução das eleições como critério de escolha dos dirigentes escolares é o interesse despertado nos vários sistemas, onde o processo se deu. Os vários depoimentos colhidos, junto a pessoas ligadas diretamente à escola ou à administração do sistema de ensino, confirmam aquilo que alguns estudos já haviam constatado, com relação ao grande comparecimento dos vários setores da escola nas eleições (Zabot, 1984; Holmesland et al, 1989; Mello, Silva, 1994).

A grande participação das pessoas nas eleições ganha significado especial, quando associada à opinião daqueles que estiveram envolvidos com o processo. Tanto nas entrevistas que fiz quanto nos estudos a respeito das eleições, em vários sistemas em que elas se deram, a maioria das pessoas tem uma opinião bastante positiva sobre os benefícios trazidos pela adoção do novo critério de escolha. Segundo um ex-assessor da Secretaria da Educação do Estado do Paraná, uma das provas de que a eleição era um processo acertado é que, nesse Estado, praticamente todas as prefeituras adotaram o processo eletivo como critério para escolha do diretor. 
Sobre o fato de a participação dos vários setores nas decisões da escola ficarem aquém do desejado, é importante atentar para as observações feitas por Calaça a propósito das eleições em Goiânia. Após considerar que, "embora esteja a escola elegendo seu diretor, já há oito anos, não se instituiu uma prática efetiva de participação dos vários segmentos em suas decisões com a conseqüente criação de canais que facilitassem esse processo", a autora pondera, entretanto, que

os vários segmentos, pelo fato mesmo de elegerem o diretor, se sentem compelidos, e bem à vontade, a fazer interlocução com o diretor. Comumente, as pessoas em conversa de "pé de ouvido" elogiam ou criticam a ação do diretor e ainda dão sugestões ou fazem reivindicações (Calaça, 1993, p.210).

Essa maior possibilidade de opinar, característica de um ambiente mais democrático, acaba levando os sujeitos envolvidos na educação escolar a uma postura mais participativa. A abertura para um diálogo mais franco certamente possibilita o surgimento de conflitos de opiniões e interesses. O que não se deve, porém, é tomar isso como algo negativo, mas considerar o que verdadeiramente se passa, isto é: a eleição de diretores, ao supor um processo de discussão e de exame crítico da realidade e dos interesses em jogo, está apenas fazendo vir à tona conflitos que permaneciam latentes e que só se resolverão de modo positivo, pelo exercício do diálogo e da democracia.

O que se observa também é que os conflitos que vêm à tona revelam uma maior consciência política que começa a se desenvolver entre os participantes do processo. Essa maior consciência política do pessoal escolar e dos usuários da escola se manifesta, quer em sua politização em termos de exigir mais do diretor eleito e do Estado, de modo geral, quer na preferência por soluções democráticas para a seleção do diretor, não admitindo um retrocesso para a escolha, pela via da simples nomeação por critério político-partidário. Tanto nos depoimentos dos 
varios sujeitos envolvidos quanto em estudos sobre o assunto (Calaça, 1993; Heemann, Pucci, 1986) é notável a preferência das pessoas pela eleição como critério de escolha dos diretores, sequer cogitando elas de outra alternativa.

Com relação aos professores, esses dados contrastam enormemente com os que foram obtidos na cidade de São Paulo, em 1991, em consulta feita entre os professores e especialistas da rede municipal, em que cerca de $81 \%$ dos docentes preferiram a escolha pela via do concurso. A hipótese que se pode levantar - sujeita, obviamente, a estudos mais aprofundados que lhe possam verificar a validade - é a de que, em ambientes onde se faz presente a discussão política da democracia e sua efetivação pela via do voto, os sujeitos estão mais propensos a concordar com essa medida do que nos locais, onde a existência do sistema de concursos, com aparência de justiça social, tem eclipsado a discussão a respeito de sua própria inadequação para atender as necessidades políticas de democracia na escola.

Uma consciência política mais desenvolvida e voltada para os interesses de todos na escola, sem restringir-se ao corporativismo estreito ou às imposições, muitas vezes antieducativas, do Estado, só poderá desenvolver-se num ambiente escolar em que todos possam conviver como sujeitos, com direitos e deveres percebidos, a partir da discussão aberta de todas as questões que afetam a vida de todos na escola. Embora a simples existência da eleição de diretores não tenha a possibilidade de instituir, por si só, esse ambiente na escola, parece certo que ela é uma prática que tem concorrido, de alguma forma, para isso. Segundo Dourado (1990, p.128), a partir da implementação das eleições, em Goiânia, "professores, funcionários, pais e alunos começaram a discutir a escola que tinham e, em alguns casos, a esboçar, ainda que preliminarmente, a escola que queriam". O citado diretor do Fórum Paranaense em Defesa da Escola Pública, Gratuita e Universal considera que o resultado positivo obtido com a eleição foi "a abertura no debate sobre as questões educativas na escola, envolvendo tanto a comunidade de dentro como a comunidade de fora". 
Essa maior discussão e maior participação, especialmente de pais e alunos, acaba contribuindo para que se dê, na escola, o desejado controle democrático do Estado, por parte dos usuários de seus serviços. No Estado de Mato Grosso do Sul, onde a eleição de diretores associouse à instalação dos colegiados escolares, Paixão constata que

algumas decisões tomadas também demonstraram mudanças na postura tradicional de gestão da escola. As audiências solicitadas à Secretaria de Educação passaram a ser feitas pelos colegiados e, em algumas ocasiões, em conjunto com a Associação de Pais e Mestres (APM). Constata-se, também, fortalecimento da ação colegiada à proporção que certas irregularidades ocorridas na escola passaram a ser encaradas com maior seriedade, havendo formalização de denúncias e instalação de sindicâncias para averiguações e possíveis correções. Desta forma, o poder compartilhado tem inibido a prática de ações irresponsáveis (Paixão, 1994, p. 114).

A circunstância de ser um colegiado e não o diretor, isoladamente, a levar suas reivindicações aos escalões superiores da Secretaria de Educação significa importante inversão na forma de pressão da escola sobre as autoridades estatais, a cujos benefícios me referi em trabalho anterior, ao relevar a importância da gestão colegiada na busca de melhor apoio para a escola, afirmando que é mais difícil dizer "não" ao pedido da escola, "quando a reivindicação não for de uma pessoa, mas de um grupo, que represente outros grupos e que esteja instrumentalizado pela conscientização que sua própria organização propicia" (Paro, 1987, p.53).

Certamente, o impacto das eleições sobre a democracia na escola ficou muito aquém do esperado pelos mais otimistas que queriam, senão todos, pelo menos um grande número de pessoas, entre pais, alunos, funcionários e professores, participando intensamente das decisões da escola pública. O que se deu, na verdade, além da ocorrência importantíssima de um novo clima de liberdade de expressão e de uma 
maior consciência de direitos e deveres, foi que a participação mais ativa ficou por conta de alguns poucos elementos mais persistentes em suas ações. Mas, a lição importante a tirar parece ser precisamente a respeito da importância de se contar com pessoas que se dispõem a participar democraticamente, porque, mesmo contando com reduzido número de adeptos atuantes, a prática democrática tem conseguido imprimir uma nova qualidade nos rumos das ações desenvolvidas no interior da escola.

A maneira de o indivíduo fazer prevalecer seus interesses, em concordância com o respeito aos direitos dos demais, é, cada vez mais, sua intervenção nos destinos da sociedade. Isto não se consegue apenas delegando as tomadas de decisão a parlamentares e executivos distantes que, em grande medida, escapam ao controle daqueles em nome dos quais o governo deve ser exercido. Por mais incipiente que ainda seja, essa participação dos indivíduos na vida dos organismos civis da sociedade apresenta, pelo menos, dois aspectos de fundamental importância para o desenvolvimento da democracia. Por um lado, à medida que se envolve com outros sujeitos (individuais ou coletivos), o indivíduo exercita sua cidadania "já que ser cidadão e ser indivíduo é algo que se aprende e é algo demarcado por expectativas de comportamentos singulares" (Da Matta, 1991, p.72). Por outro lado, ao intervir com sua opinião e explicitação de seus interesses, procurando influir nas decisões que se tomam nos órgãos e instâncias, onde se realizam as atividades-fim do aparelho estatal (escolas, atendimento de saúde, transportes etc), os cidadãos contribuem para realizar o controle democrático do Estado, concorrendo, para que este atue, de acordo com os interesses da população que o mantém.

Uma análise consistente da realidade escolar brasileira mostra que a atual situação de precariedade da escola pública só poderá ser superada a partir de forte vontade política dos governantes, que se concretize na necessária atenção para com o ensino e no provimento dos recursos imprescindíveis para a realização de uma escola pública de 
qualidade. A esse respeito, a eleição de diretores não tem o imediatismo que muitos desejariam. Seu papel é apenas o de contribuir, para que a população possa contar com um recurso que lhe possibilite exercer alguma pressão sobre o Estado, para que ele atue na direção desejada. Em síntese, a razão determinante da opção pela eleição, como mecanismo de seleção de diretores, é a crença de que, por um lado, pode-se escolher um profissional que se articule com os interesses da escola, e por outro, o próprio método de escolha condiciona, em certa medida, seu compromisso, não com o Estado, como fazem as opções do concurso e da nomeação, mas com os servidores e usuários da escola. Mas, por mais importante que seja esse comprometimento - porque deixa aberta a possibilidade de o diretor, articulando-se com usuários e servidores, pressionar o Estado - ele é apenas um recurso para melhorar a escola, não uma certeza. Tudo dependerá do jogo de forças envolvidas, que não é função, obviamente, apenas da eleição do diretor.

Referências bibliográficas

CALAÇA, Celina Ferreira. Eleição de diretor de escola e gestão democrática: um estudo de caso. São Paulo, 1993. Dissertação (Mestrado) - PUC-SP.

CANESIN, Maria Tereza. Um protagonista em busca de interlocução: um resgate da história do movimento de professores da rede pública de $1^{\circ} \mathrm{e} 2^{\circ}$ graus em Goiás, na conjuntura 1979/1989. São Paulo, 1993. Tese (Doutorado) - PUC-SP.

CASTRO, Marta Luz Sisson de et al. Eleição de diretores: a experiência do Estado do Rio Grande do Sul. Revista Brasileira de Administração da Educação, Brasília, v.7, n.1/2, p.80-102, jan./dez. 1991. 
COUTO, Jurema Barbieri. Gestão democrática na escola pública: o caso do Distrito Federal (1985-1988). Brasília, 1988. Dissertação (Mestrado) - Faculdade de Educação-UnB.

Da MATTA, Roberto. A casa \& a rua: espaço, cidadania, mulher e morte no Brasil. 4.ed. Rio de Janeiro: Guanabara, 1991.

DOURADO, Luis Fernandes. Democratização da escola: eleições de diretores, um caminho? Goiânia, 1990. Dissertação (Mestrado) Faculdade de Educação-UFG.

HEEMANN, Eliana Barbosa, PUCCI, Francisco César de Luca. A eleição dos diretores das escolas estaduais do Paraná e seus efeitos na vida da escola. Curitiba: Universidade Federal do Paraná, 1986.

HELLER, Agnès. Para mudar a vida: felicidade, liberdade e democracia. São Paulo: Brasiliense, 1982.

HOLMESLAND, Içara da Silva et al. A liderança nas escolas na nova democracia social: uma análise interestadual. Porto Alegre, 1989. (Relatório de Pesquisa).

LEAL, Elisabeth Juchem Machado, SILVA, Virgínia Maria de Figueiredo e. Diretores eleitos: dilemas emergentes da greve do magistério de 1987 em Santa Catarina. Revista Brasileira de Administração da Educação, Porto Alegre, v.5, n.1, p.62-77, jan./ jun. 1987.

MELLO, Guiomar Namo de, SILVA, Rose Neubauer da. Seleção competitiva de diretores: estudo de caso de uma inovação educacional no Brasil. Estudos em Avaliação Educacional, São Paulo, n.10, p.745, jul./dez. 1994. 
PAIXÃO, Regina da. O colegiado escolar como instrumento de gestão participativa: a vivência de Mato Grosso do Sul. In: XAVIER, Antonio Carlos da R., AMARAL SOBRINHO, José, MARRA, Fátima (Org.). Gestão escolar, desafios e tendências. Brasília: Ipea, 1994. p. 107-122. (Série Ipea, 145).

PARO, Vitor Henrique. Administração escolar, introdução crítica. São Paulo: Cortez, Autores Associados, 1986.

- Eleição de diretores: a escola pública experimenta a democracia. Campinas: Papirus, 1996.

. A utopia da gestão escolar democrática. Cadernos de Pesquisa, São Paulo, n.60, p.51-53, fev. 1987.

SÁNCHEZ VAZQUEZ, Adolfo. Filosofia da praxis. 2.ed. Rio de Janeiro: Paz e Terra, 1977.

ZABOT, Nircélio. Eleições para diretores escolares: uma importante conquista democrática. Revista Brasileira de Administração da Educação, Porto Alegre, v.2, n.1, p.88-91, jan./jun. 1984.

. O regimento escolar como instrumento de organização administrativa e pedagógica da comunidade escolar. Revista Brasileira de Administração da Educação, Porto Alegre, v.4, n.2, p.63-66, jul./dez. 1986.

Recebido em 20 de janeiro de 1997.

Vitor Henrique Paro é professor do Departamento de Administração Escolar e Economia da Educação da Faculdade de Educação da Universidade de São Paulo (Usp). 
Supported by a research that focused the use of elections in the selection of public elementary school principals in several Brazilian educational systems, the article inquires some setbacks of this experience and also discusses aspects related to the impact of elections on the role of principals and on the practice of democracy in the school administration.

Il s'agit d'abord d'une recherche qui a étudié l'introduction du système d'élection de directeurs d'écolespubliques élémentaires dans des systèmes les plus divers d'enseignement au Brésil. Basé dans cette recherche, l'article examine quelques limitations de l'experience élective dans les écoles et discute des aspects relationés à l'impact des élections sur le rôle du directeur et sur la pratique démocratique dans la gestion de l'école publique.

Basado en investigación que estudió la introducían del sistema de elección de directores de escuelas públicas básicas en varios sistemas de enseñanza en Brasil, el artigo examina algunos limites de la experiencia electiva en las escuelas y discute aspectos relacionados al impacto de las elecciones sobre el rol del director y sobre la práctica democrática en la gestión de la escuela pública. 